\title{
Clinical Case of Malignant Acrospiroma, Treatment Results Evaluation
}

\author{
Hojouj Mohammad, I. Bondarenko, V. Zavizion, Urzhumova N, Astakov A, Soloviova N, Bondarenko Y, Stan .N, Elhaj M, Bilinka I \\ Department of oncology and medical radiology, Municipal Institution “Dnipropetrovsk City Multi-field Clinical Hospital, Volodymyr Vernadskii str, \\ Ukraine \\ *Correspondence to: Hojouj Mohammad, Department of oncology and medical radiology, Municipal Institution «Dnipropetrovsk City Multi-field Clinical Hospital, \\ Volodymyr Vernadskii str, Ukraine; Email: hojouj@yahoo.com
}

Received: August 04, 2017; Accepted: August 15, 2017; Published: August 23, 2017;

\section{Introduction}

Malignant acrospiroma (MA) - is rather rare tumor with eccrine ductal and secretory differentiation, including clear cell component. This type of tumor appears more often in elderly people (average male patient age is 51 years, female patient - 55 years). The tumor corresponds to solitary intradermal, exophytic or mixed type node $0.5-2 \mathrm{~cm}$ or more in diameter, hemispheric, tight-elastic texture, on wide base, covered with unchanged skin, sometimes with ulcers. Small percent of cases have clear discharge from tumor. Considering the same architecture of malignant nodular hydradenoma and benign analogue, it is difficult to find the difference between them, although undisputed manifestation of malignance is vessel and perineural invasion, lymphogenic metastasis.

The tumor is very aggressive and liable to metastasis. It is important to notice that there are no direct histological and clinical signs, predicting biological behavior of the tumor. Despite chemotherapy, patients with metastasis has fatal outcome vary rapidly. There no proved data of chemotherapy impact on malignant acrospiroma.

\section{Description of MA clinical case}

Patient, 58 years, applied to Dnipropetrovsk Multi-field Clinical hospital \#4 in Jan 2017 to the Department of Oncology and Medical Radiology of Dnipropetrovsk Medical Academy with complaints to fatigue and tumor formation.

\section{Anamnesis}

Patient consider himself sick since Autumn 2016, when above mentions complaint appeared for the first time. Incisional biopsy was performed in Nov2016, and then the patient was sent to the Department of Oncology and Medical Radiology of the Dnipropetrovsk Multiffield Clinical Hospital \#4

Pathohistological conclusion as of 16 Nov 2016:

Tumor has the structure of malignant eccrine acrospiroma with ulceration.

\section{Life history}

Catarrhal diseases are 1-2 times per year. No addictions. No allergies. No hemotrasfusions, traumas and surgeries. Diabetes mellitus type II, more than 2 years. No cancer family history.

\section{Physical examination}

Formation in left parietal region, round in shape with indeterminate boundaries, $2 \mathrm{~cm}$ in diameter, with tissue lysis and perifocal inflammation.

\section{Investigation data}

1. Pathohistological conclusion №10291-96/16 as of 16 Nov 2016: Tumor has the structure of malignant eccrine acrospiroma with local ulceration.

2. X-ray assessment of the chest as of 11 Jan 2017: Radiological signs of metastasis in lungs.

3. Endocrinologist assessment as of 13 Jan 2017: Diabetes mellitus type II, compensated.

4. Therapeutist assessment as of 13 Jan 2017: Essential hypertension II gr. Coronary heart disease: atherosclerotic cardiosclerosis, Heart failure I.

5. CT assessment of chest, abdominal cavity and pelvis as of 17 Jan 2017: CT-signs of multiple secondary changes on lungs, increased mediastinal lymph nodes, metastasis in liver S4. Cholelithiasis. Concernments in right kidney. Mass lesion in left lobe of thyroid gland.

6. CT assessment of brain as of 17 Jan 2017: CT-signs of encephalopathy.

7. Echocardiography as of 20 Jan 2017: Satisfactory myocardial contractility, LVEF - $60 \%$

8. Punctate from thyroid gland as of 26 Jan 2017: Accumulation of polymorphic cells of follicular epithelial tissue, stroma elements.

9. CA results as of $20 \mathrm{Jan} 2017: 19.05 \mathrm{U} / \mathrm{mL}$. 
10. Hematology as of $13 \operatorname{Jan} 2017$

- HB $120 \mathrm{~g} / \mathrm{L}$

- $\quad$ RBC $4.08 \times 10^{12} / \mathrm{L}$

- WBC $7.56 \times 10^{9} / \mathrm{L}$

- SOE $28 \mathrm{~mm} / \mathrm{h}$

- lymphocytes $28.7 \%$

- monocytes $11.8 \%$

Hematology was done 2 days before chemotherapy and 5 days after. Patient had chemotherapy-induced leucopenia and neutropenia grade I-II CTC AE, recovered after drug administration. No chemotherapy cycles delayed.

11. Hematology as of $03 \mathrm{Jul} 2017$

- $\mathrm{HB} 134 \mathrm{~g} / \mathrm{L}$

- $\operatorname{RBC} 4.58 \times 10^{\wedge} 12 / \mathrm{L}$

- WBC $5.34 \times 10^{\wedge} 9 / \mathrm{L}$

- $\operatorname{SOE} 8 \mathrm{~mm} / \mathrm{h}$

- lymphocytes $28.7 \%$

- monocytes $6 \%$

12. Chemistry as of 13 Jan 2017

- total bilirubin $-7.3 \mathrm{mmol} / \mathrm{L}$

- $\mathrm{ALT}-21 \mathrm{IU} / \mathrm{L}$

- AST - $23 \mathrm{IU} / \mathrm{L}$

- total protein $-55.8 \mathrm{~g} / \mathrm{L}$

- alkaline phosphatase - $74 \mathrm{IU} / \mathrm{L}$

13. RW as of 13 Jan 2017 - negative

14. AID as of 13 Jan 2017 - negative

15. Hepatitis B and C as of 13 Jan 2017 - negative

\section{Diagnosis}

Malignant acrospiroma, $\mathrm{T}_{2} \mathrm{~N}_{0} \mathrm{M}_{1}$ stage IV ( $\mathrm{mts}$ in lungs and liver), clinical group 2

Clinical case was discussed on board of doctors. Chemotherapy was prescribed.

Received treatment:

1. Carboplatin - VISTA AUG 6

2. Docetaxel - VISTA $75 \mathrm{mg} / \mathrm{m}^{2} \mathrm{IV}$

3. Fluorouracil - VISTA $500 \mathrm{mg} / \mathrm{m}^{2} \mathrm{IV}$

Visual clinical dynamics in the course of the treatment.

\section{Recommendation at discharge}

1. Family doctor supervision

2. Control blood analysis in 7-21 days.

3. CT assessment of chest, abdominal cavity and pelvis after 3 months:

\section{Complete diagnosis at discharge}

Malignant acrospiroma, $\mathrm{T}_{2} \mathrm{~N}_{0} \mathrm{M}_{1}$ stage IV ( $\mathrm{mts}$ in lungs and liver), condition after non-radical surgery, after 8 cycles of chemotherapy clinical group II.

Patient had positive dynamics after chemotherapy treatment, complete response as per RECIST 1.1. Patient had not complaints.

CT assessment of chest, abdominal cavity and pelvis with IV contrast as of 28 Jun 2017: CT-signs of stable size of thyroid gland left lobe formation, positive dynamics due to disappearance of lesions in lungs, mediastinal lymph nodes, liver lesions. No new lesions.

Patient has fully active lifestyle, and he is under family doctor and oncologist supervision [Figure 1].

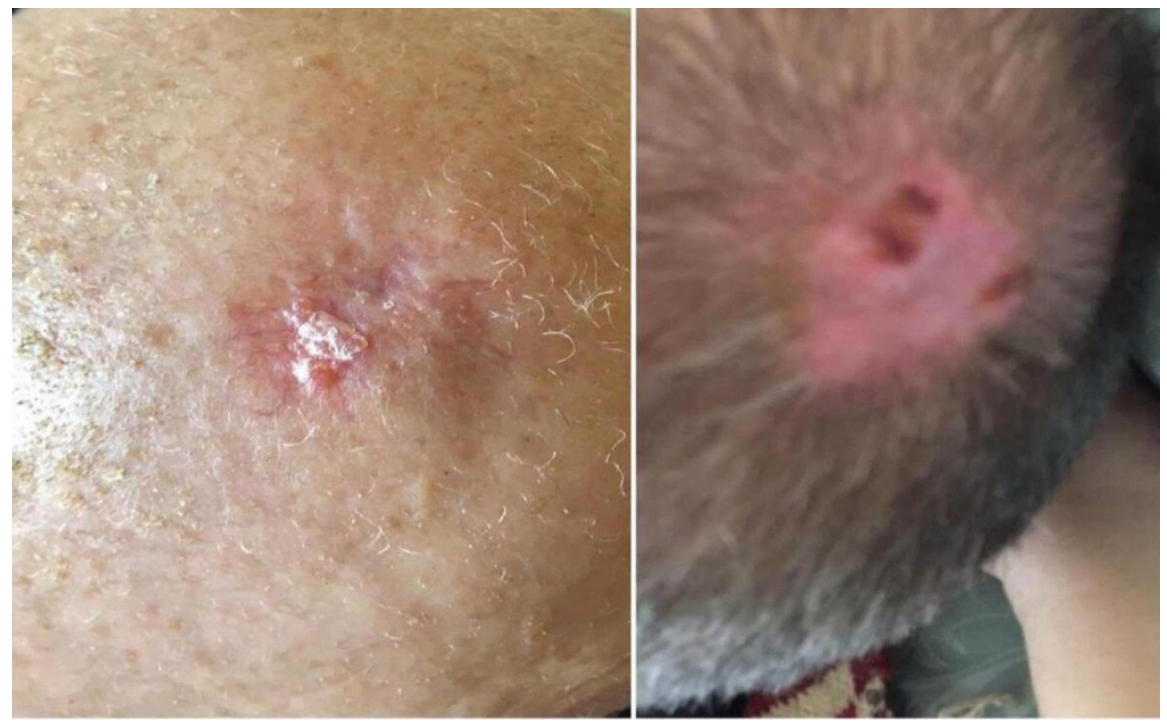




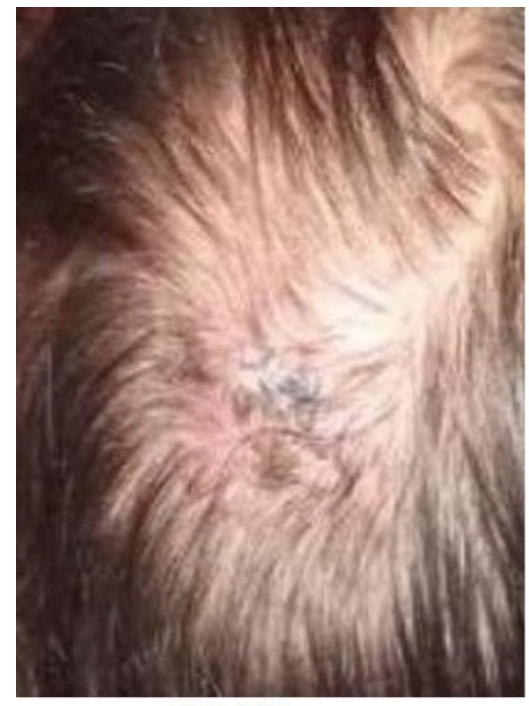

19.01.2017

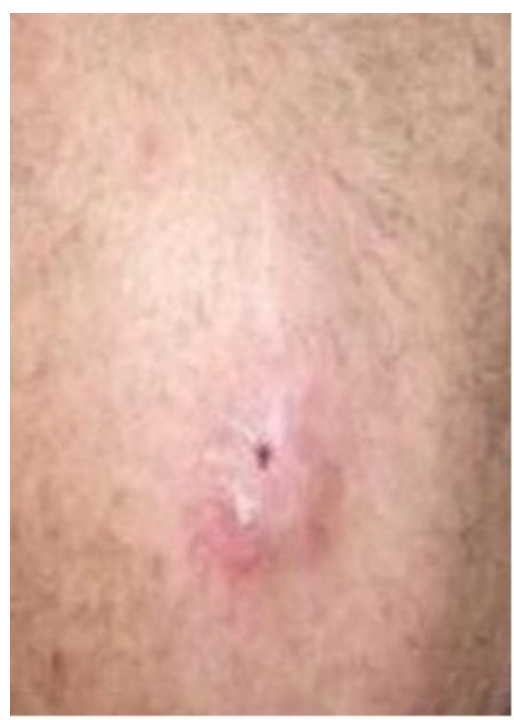

22.03.2017

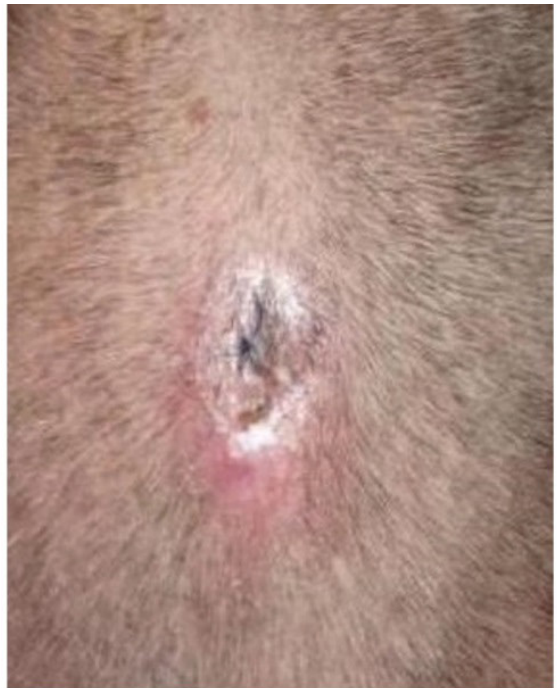

08.02.2017

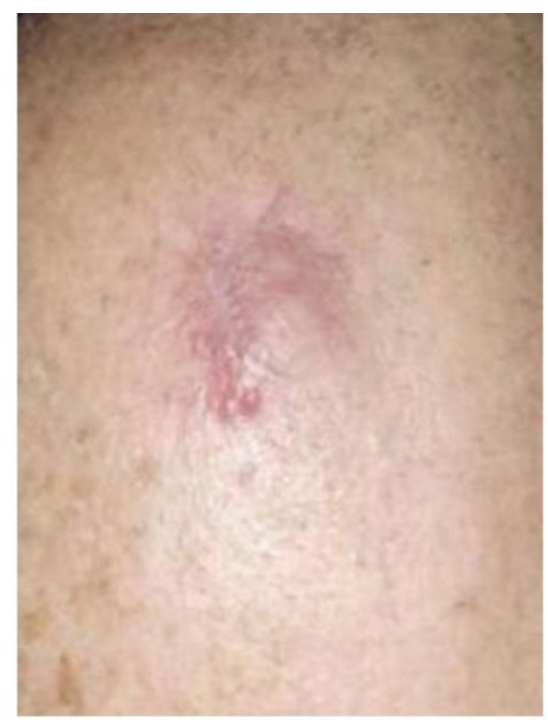

12.04.2017

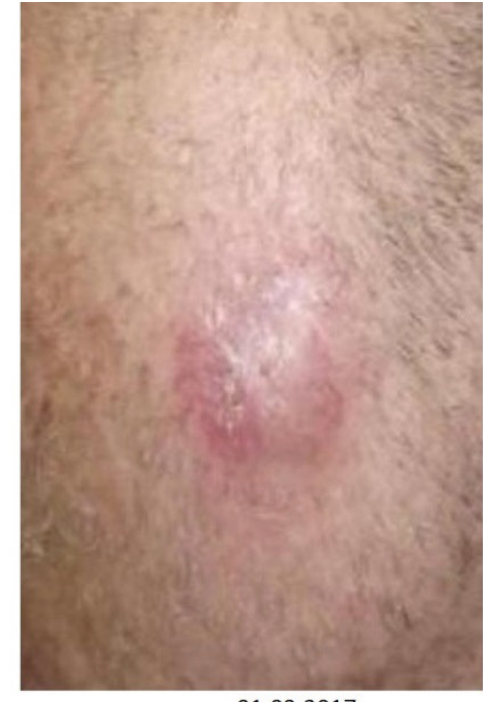

01.03.2017

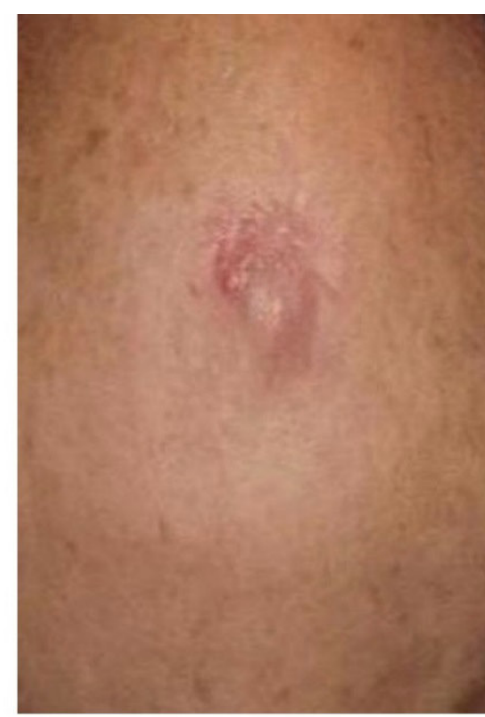

03.05.2017

Figure 1: Clinical Case of Malignant Acrospiroma

\section{Citation:}

Hojouj Mohammad, I. Bondarenko, V. Zavizion, Urzhumova N, Astakov A, Soloviova N, Bondarenko Y, Stan .N, Elhaj M, Bilinka I (2017) Clinical Case of Malignant Acrospiroma, Treatment Results Evaluation. Cancer Stud Ther J Volume 2(4): 1-3 